\title{
VERTENTES DA EDUCOMUNICAÇÃO: A EXPERIÊNCIA DE ATUAÇÃO DA AGÊNCIA DE NOTÍCIAS VAN NA FORMAÇÃO DE LEITORES CRÍTICOS DA MÍDIA
}

\author{
ASPECTS OF EDUCATIONAL COMMUNICATION: THE EXPERIENCE \\ OF NEWS AGENCY VAN IN THE FORMATION OF MEDIA'S CRITICAL \\ READERS
}

\author{
Ivan Vasconcelos Figueiredo ${ }^{1}$; Filomena Maria Avelina Bomfim² \\ Rhafaela Dáfni Alves Resende ${ }^{3}$; Barbara Cristina Beloti Barreto ${ }^{4}$; Ana Claudia Lima ${ }^{5}$
}

\begin{abstract}
RESUMO
O presente artigo apresenta a experiência de articulação entre Educação e Extensão na UFSJ, especificamente, as ações extensionistas e educomunicativas do Programa "Vertentes Agência de Notícias" na formação de leitores críticos da mídia na Escola Estadual Dr. Garcia de Lima. A metodologia selecionada é estudo de caso, a partir do qual são apresentadas e debatidas as práticas educomunicativas empreendidas de agosto a outubro de 2013na referida instituição de ensino. Avaliase que os jovens, convocados à ação, por meio de estratégias de empoderamento do fazer jornalístico, passaram a se engajar na reflexão e construção das próprias representações do cotidiano. $O$ jornal mural apresenta-se, assim, como um instrumento para proporcionar a elevação do aparato críticoapreciativo dos receptores, que passam a atuar como agentes multiplicadores dessa iniciativa entre os colegas de outros turnos, passando a colaborar para a transformação de um alunado passivo, em parceiros ativos e responsáveis pela construção de um processo ensino-aprendizagem centrado no desenvolvimento da cidadania.
\end{abstract}

Palavras-chave: Educomunicação. Jornalismo regional. Formação de leitores.

\begin{abstract}
This paper presents the experience of UFSJ in its attempts to articulate Education and Extension. It focuses specifically, extension activities and educational communication in the extension Programme named as "Vertentes Agência de Noticias". This initiative aims to develop a critical approach towards reading among Dr. Garcia de Lima secondary school's students. The methodology of work is the case study. It means practices of educational communication developed from August to October of 2013 were presented and discussed by secondary school students. As a result, it is estimated that young people, called to action through empowerment strategies in journalism, began to engage in reflection and construction of social representations of reality themselves everyday. The bulletin board is presented as medium to improve the critical apparatus of the receptors. These students can also perform as multipliers of this initiative among schoolmates from other levels. Therefore they tend to be able to work for their own transformation from passive students into active partners who are responsible for the construction of a teaching-learning process focused on the development of citizenship in their communities.
\end{abstract}

Keywords: Educational communication. Regional journalism. Educating readers process.

\footnotetext{
${ }^{1}$ Universidade Federal de São João del-Rei. Email: ivanvasconcelos@ufsj.edu.br

${ }^{2}$ Universidade Federal de São João del-Rei .Email: myosha@gmail.com

${ }^{3}$ Universidade Federal de São João del-Rei. Email: rhafaelaresende@gmail.com

${ }^{4}$ Universidade Federal de São João del-Rei. Email: barbarabeloti@gmail.com

${ }^{5}$ Universidade Federal de São João del-Rei. Email: anacs12009@hotmail.com
} 


\section{INTRODUÇÃO}

As agências de notícias cumprem uma missão fundamental na sociedade: captar e levar as informações aos veículos que não teriam condições de apurá-las nas mais diversas cidades, regiões e países. Convencionalmente, pensa-se nestas agências como grandes indústrias internacionais, porém, neste trabalho, mostramos as possibilidades de atuação regional da Vertentes Agência de Notícias (VAN) no Campo das Vertentes, em Minas Gerais.

Mais do que apurar, redigir e distribuir notícias e reportagens a serem aproveitadas pela imprensa, as agências de notícias têm o potencial de transformar a realidade na qual estão inseridas, atuando diretamente na formação do cidadão para que este faça uma leitura mais crítica da mídia e das informações recebidas. Assim, o presente estudo evidencia a intervenção social da VAN, enquanto Programa de Extensão da Universidade Federal de São João del-Rei, no ensinodo "fazer jornalístico" em oficinas direcionadas a estudantes de Ensino Médio da rede pública de São João del-Rei/MG.

Em um primeiro momento, discutimos a relevância da Educomunicação como instrumento e arcabouço teórico-metodológico para articular entre Extensão e Educação, bem como discorremos sobre os potenciais transformadores de práticas educomunicativas extensionistas na formação de leitores críticos da mídia por meio da troca de saberes. Em seguida, apresentamos o funcionamento da Agência de Notícias VAN. Por fim, as experiências das oficinas de mídia cidadã são relatadas com base na metodologia de estudo de caso, conforme conceituação de Yin (2001), fornecendo as bases para a compreensão dos fenômenos individuais, organizacionais, sociais e políticos vivenciados pelos agentes da VAN e estudantes de Ensino Médio. Nesse escopo, cabe notar que as análises aqui efetuadas restringem-se, com isso, ao universo estudado e não devem ser vistas em uma perspectiva generalizante.

\section{EDUCOMUNICAÇÃO E JORNALISMO REGIONAL}

O conceito de Educomunicação não surgiu no Brasil, tendo contado com a contribuição teórica-prática de filósofos da educação, tais como Célestin Freinet e Paulo Freire, bem como de estudiosos da comunicação, como Jesús Martín-Barbero e Mário Kaplún. Por meio de reflexões e trabalhos de campo, esses intelectuais promoveram a aproximação entre o avanço das conquistas tecnológicas e o barateamento dos custos dos 
equipamentos, levando grupos ativos e organizados de especialistas a iniciarem um irreversível processo de aproximação entre os campos da Comunicação e da Educação.

Assim sendo, diversos autores trabalharam em sua definição, sendo que, no Brasil, o professor Ismar de Oliveira Soares tem se destacado como referência na matéria. Ele define tal campo de mediações como uma "forma de conhecer e compartilhar o conhecimento usando estratégias e produtos de comunicação" (Rede CEP, 2010, p. 11). De uma forma geral, a Educomunicação busca garantir o acesso à comunicação, promovendo a ampliação da capacidade de expressão e o conhecimento que o indivíduo tem de si mesmo e do outro.

O campo da Educomunicação é vasto e abrange diversas perspectivas, dentre elas a comunicação comunitária e o uso da tecnologia para promover a educação. Desta forma, por meio da Educomunicação, os meios de comunicação, até então, utilizados pelos veículos de massa passam a ser utilizados também pelas instituições de ensino, alunos e professores para promover o aprendizado como ação colaborativa a serviço da comunidade em geral.

Paulo Freire contribuiu com sólidos estudos sobre a relação entre a comunicação e a educação, buscando sempre potencializar o aprendizado, a partir da formação de cidadãos críticos comprometidos com o desenvolvimento de seu contexto imediato. Para Freire, a educação diz respeito ao compartilhamento do conhecimento e deve refletir reciprocamente entre o educador e o aluno, entendidos como parceiros responsáveis pelos objetivos alcançados. Para ambos, a comunicação atrelada à educação deve resultar em um processo de aprendizado mútuo, por meio da troca de experiências, rompendo com a concepção de educação bancária. "O educador já não é mais o que apenas educa, mas o que enquanto educa, é educado, em diálogo com o educando que, ao ser educado, também educa. [...] Os homens se educam em comunhão, mediatizados pelo mundo" (FREIRE, 1978, p. 39).

O conceito de educação bancária interpreta o educando como um receptor passivo, que apenas recebe o conhecimento e tem como único papel decorá-los. Essa dinâmica mantém a relação entre aluno e professor polarizada, delimitando os que detém o conhecimento e os que recebem sem questionar a informação. Por isso, no contexto freireano, tal prática caracteriza o educador como um opressor, uma vez que o mesmo define o conteúdo a ser "depositado" sem que haja um diálogo com os mais interessados na mensagem, ou seja, os educandos. Essa estratégia dificulta o estabelecimento de uma relação proveitosa entre os atores do processo, de forma que, sem a troca de ideias ou debate, cada um se isola em sua própria zona de conforto, reforçando os pressupostos da comunicação pessoal, defendida por José Manuel Moran (1993). 
Por outro lado, na contemporaneidade, a comunicação tem caminhado na direção da participação, da integração, da inclusão de pessoas diferentes e de suas formas distintas de encarar a realidade. Nesse processo, ocorre a aproximação de mais pessoas, de mais grupos; no estabelecimento de vínculos, desprezando a formação de grupinhos, "panelinhas" ou seitas. Pela comunicação das emoções, sentimentos e afetos em múltiplas plataformas e de várias formas nas diversas mídias, inclusive, nas redes sociais.

Reforçando esse cenário, Freire propõe uma nova forma de educar, tendo o diálogo como protagonista e um caráter reflexivo. Trata-se da educação "problematizadora" ou dialógica. Neste modelo, a construção/transmissão do conhecimento de forma recíproca pode promover a reflexão sobre o conhecimento captado, o raciocínio crítico, como explica: “[...] a educação problematizadora que [...] busca a expansão das consciências, em prol de sua inserção crítica e transformadora na realidade" (FREIRE, 1978, p. 80).

Outro estudioso do tema, Mario Kaplún, reforça a ideia da inter-relação entre a comunicação e a educação. "A cada tipo de educación corresponde una determinada concepción y una determinada práctica de la comunicación” (KAPLÚN, 1996, p. 17). O autor também é contra o modelo de comunicação verticalizado, afirmando que a prática do monólogo distancia as pessoas do sentimento de comunhão, que deveria permear a sociedade. Mas, como ele mesmo afirma, tal prática "está firmemente implantada en la sociedad e internalizada en el tejido social" (KAPLÚN, 1997, p. 1).

Kaplún lamenta que exista cada vez mais informação e menos formação. Para ele, mais do que transmitir a informação, o comunicador deve estimular discussões e o pensamento crítico dos receptores, que, por sua vez, devem se inserir ativamente no processo ensino-aprendizagem, discutindo, acrescentando e contribuindo efetivamente para a construção de uma realidade em que o acesso à informação seja garantido à maioria dos cidadãos.

Neste Programa de Extensão, o aprofundamento da discussão do conceito de Educomunicação acontece em encontros quinzenais, dos quais participam os discentes do Curso de Comunicação envolvidos na iniciativa, além dos alunos do Curso de Filosofia que, pelo fato de estarem matriculados em um curso de licenciatura, já tem o hábito de entrar em salas de aula. Como essa não constitui uma peculiaridade dos cursos de Comunicação Social, o compartilhamento das experiências entre os estudantes das duas graduações tem sido um momento de notório enriquecimento intelectual, tendo em vista as trocas de experiências analisadas a partir dos referenciais teóricos diferentes dos dois cursos. Assim sendo, a 
abordagem distinta desses grupos, os discursos e posturas permitem/fomentam não apenas o intercâmbio de vivências, mas, principalmente, a identificação de questões de alteridade consideradas apenas do ponto de vista teórico, fundamentais para o pleno exercício das práticas extensionistas.

\section{ECOSSISTEMAS COMUNICATIVOS E EDUCOMÍDIA}

Na Biologia, o conceito de ecossistema se refere a um conjunto dos seres vivos, ao ambiente em que vivem e todas as interações entre esses organismos e o meio entre si. Um ecossistema está sempre em transformação e sofre a ação de fatores externos a ele. No campo da Educomunicação, os Ecossistemas Comunicativos "estão se convertendo em algo tão vital como o ecossistema verde, ambiental" (MARTÍN-BARBERO, 2000, p. 54). Para o autor, a informação descentralizada facilita o acesso ao conhecimento por meio da utilização criativa e contextualizada dos meios de comunicação (como recursos didáticos) em sala de aula. Assim sendo, tanto as mídias alternativas quanto as novas tecnologias, por sua vez, podem atuar como grandes aliadas nesse processo.

É aí que se situa a segunda dinâmica que configura o ecossistema comunicativo no qual estamos imersos: O saber é disperso e fragmentado e pode circular fora dos lugares sagrados nos quais antes estava circunscrito e longe das figuras sociais que o administravam (MARTÍN-BARBERO, 2000, p. 54-55).

Ismar de Oliveira Soares também discorre sobre os ecossistemas educomunicativos, classificando-os como ambientes que "cuidam da saúde e do bom fluxo das relações entre as pessoas e os grupos humanos, bem como do acesso de todos ao uso adequado das tecnologias da informação" (SOARES, 1999).

A união dos campos de Educação e dos canais midiáticos com o objetivo de potencializar o aprendizado também pode ser chamada de educomídia, como bem explica Marques de Melo (2006). Um exemplo disso é a produção de conteúdo por parte dos estudantes, como ocorre na Vertentes Agência de Notícias (VAN), em que discentes aprendem a fazer matérias jornalísticas, a partir da troca de experiências com colegas de períodos mais adiantados no Curso, sob a supervisão de um professor coordenador de área. Nesse ambiente, privilegia-se a proatividade, o espírito colaborativo, a participação espontânea, o que permite e estimula a criatividade, o trabalho em grupo e o compromisso 
com a formação de todos e de cada, em um "laboratório" de experimentação de práticas narrativas e redacionais. Ou seja, apesar do contexto diferente, a preocupação com a intervenção social por meio das práticas comunicativas e pedagógicas, é a mesma de autores como Freire e Freinet.

Nas palavras de Marques de Melo,

A Educomídia é um campo emergente de intervenção social e de prática profissional que pode ser vista como área de especialização na qual o comunicador e o educador se somam com o objetivo de serem produtores e agentes de um processo social, tendo como protagonista grupos populares, resultado de uma necessidade contemporânea que exige de ambos um papel educativo. (FERRARI IN: MARQUES DE MELO et al., 2006, p. 10).

\section{JORNALISMO REGIONAL}

Cicília Peruzzo (2005) analisa que o jornalismo local/regional tem sido tratado mais como um nicho de mercado pelas indústrias midiáticas, relegando-se a produção de conteúdo em si. Neste plano, a referida autora aponta que existem algumas tendências que comprometem a qualidade da informação: a primeira delas é o forte vínculo político, o qual incorre em tratamento tendencioso e omissão de fatos; a segunda é o aproveitamento de releases (sugestões de pauta) sem a devida apuração e complementação das informações, em que a maioria das notícias advém das assessorias de instituições públicas e privadas; o terceiro aspecto refere-se à ausência de ampla cobertura e apuração dos acontecimentos nos âmbitos local e regional, com aproveitamento de conteúdos de agências de notícias nacionais em detrimento da notícia local. Para Peruzzo (2005, p. 81), "nessas condições, o jornalismo local deixa de explorar seu imenso potencial de trabalhar com a informação isenta e atender a todos os setores que perfilam a vida de uma 'comunidade"'. Na visão da autora, as pessoas possuem interesse em ver os temas da localidade retratados na imprensa regional.

Diante desse retrato do fazer jornalístico local e regional, a VAN procura preencher parte dessas lacunas informacionais ao promover a cobertura jornalística não atrelada a convicções mercadológicas e políticas, oferecendo conteúdo que se diversifica nas abordagens temáticas e enquadramentos das fontes, bem como explora informações que os veículos midiáticos locais e regionais poderiam não cobrir.

Adicionalmente, Peruzzo (2005) acrescenta que o jornalismo local refere-se àquelas práticas que retratam a realidade regional ou local, priorizando, portanto, a informação de 
proximidade. Isto quer dizer que o meio de comunicação local tem a possibilidade de mostrar melhor do que qualquer outro a vida em determinadas regiões, municípios, cidades, vilas, bairros, zonas rurais, dentre outros. É bem verdade que, por vezes, se cerca de distorções, como as que têm origem em vínculos com interesses político-partidários e econômicos, mas, mesmo acarretando vieses de informação, acaba contribuindo na divulgação de temas locais. Insere-se, portanto, em um contexto vantajoso para o leitor ou telespectador, ou seja, a proximidade da informação. Nesse ambiente, o público-alvo acompanha os acontecimentos de forma mais direta, pela vivência ou presença pessoal, o que possibilita o confronto entre os fatos e sua versão midiática de forma mais natural, acarretando, portanto, uma cobrança com relação ao cumprimento dos interesses locais.

\section{A VAN E A FORMAÇÃO DE LEITORES CRÍTICOS DA MÍDIA}

O Programa de Extensão Universitária "Vertentes Agência de Notícias" (VAN) nasceu em 2010 como um trabalho de sala de aula durante a disciplina Jornalismo Internacional,no Curso de Comunicação Social/Habilitação Jornalismo da UFSJ. A proposta começou a ser realizada como um link do site Jornal das Lajes, periódico local da cidade de Resende Costa/MG e, posteriormente, a VAN passou a operar em um site independente: www.vanufsj.jor.br.

A atividade extensionista da VAN pretende aproximar a prática do jornalismo internacional do regional, preenchendo a lacuna jornalística de ausência de repórteres correspondentes em outras cidades. Na região do Campo das Vertentes, em Minas Gerais, a intenção é cobrir os 22 municípios da mesorregião de São João del-Rei/MG, oferecendo informações que as mídias locais e regionais não poderiam cobrir. Além disso, promove e estimula a pesquisa sobre as repercussões de eventos internacionais na região, destacando sobremaneira as questões locais, que passam a usufruir de status privilegiado.

Desde 2013, o Programa organiza-se em quatro áreas integradas, a saber:

a) O Eixo 1 é composto pela Coordenação Geral, a qual comanda a produção de conteúdo de interesse regional, levantamento de pautas, mapeamento de fontes e definição de estratégias de relacionamento com os públicos da agência e formas de apresentação e distribuição multimídia do conteúdo. 
b) O Eixo 2 é formado pela Subcoordenação de Revisão de Textos e Práticas Educomunicativas, que realiza a revisão textual das notícias a serem postadas no site da VAN e encaminhadas à mídia regional. Este eixo também está articulado com a estratégia educomunicativa no processo de revisão textual, a partir da qual os alunos vão avaliar suas produções e entender como melhorar a escrita jornalística atenta às demandas informacionais da comunidade regional.

c) O Eixo 3 é fomentado pela Subcoordenação de Multimeios, que articula distintos dispositivos para a representação dos fatos: fotos, vídeos, infográficos, hiperlinks e áudio passam a complementar e oferecem uma imersão na dimensão textual da notícia e reportagem divulgada no site da VAN. O Multimeios prioriza a experimentação na complementaridade de códigos, tendo em vista as novas potencialidades e características da web. Assim, pretende-se que o leitor possa ter uma imersão e aprofundamento nos conteúdos por meio de diferentes meios (impressos, digitais, audiovisuais) e que os estudantes, em interação com a comunidade, tenham a experiência do uso de diferentes recursos para trabalhar a produção, divulgação e reflexão sobre a informação de cunho jornalístico. Nessa dinâmica, os estudantes de Jornalismo são incentivados a melhorar suas capacidades de comunicação escrita, oral e visual. Na prática, elesaprendem a trabalhar de forma independente, respeitando prazos. Neste cenário, são incentivadas as habilidades de gerenciamento de tempo e relacionamento com as pessoas. Ademais, seus trabalhos darão visibilidade a seus currículos, colaborando para a conquista de uma oportunidade no mercado de trabalho, num futuro próximo.

d) O Eixo 4 é articulado pela Subcoordenação de Assessoria de Comunicação, a qual planeja e executa estratégias de relacionamento interno e externo na VAN. O foco desse trabalho está:(I) na ampliação e fortalecimento das relações da agência com as mídias regionais (vistas como parceiras na difusão dos conteúdos produzidos pelos redatores da Agência), por meio de visitas, contatos diários e encaminhamentos de pautas, além de dois Encontros Regionais;(II) captação e fidelização de leitores por intermédio das redes sociais, a partir de monitoramento do site oficial e canal no Facebook;(III) formação de cidadãosleitores críticos da mídia em São João del-Rei com duas oficinas de Mídia-Educação direcionada a estudantes da Rede Pública de Ensino Fundamental;(IV) produção e divulgação de eventos acadêmicos, culturais e informacionais.

Por meio da prática extensionista articulada ao ensino e pesquisa, a VAN pretende contribuir para a estrutura social vigente, produzindo notícias que estimulem práticas de leitura capazes de proporcionar a reflexão sobre o cotidiano e a história em curso. Entende-se 
que a leitura crítica não é natural ao sujeito, sendo necessária uma aliança direta que estimule o hábito e aprendizado em comunidade. Essa atuação transformadora requer a concepção de relacionamento, de troca de saberes entre a universidade e a esfera social, em que a VAN passe a ter acesso às demandas e interesses do público-alvo e ofereça, em contrapartida, conteúdos informativos adequados às necessidades e características da mídia e moradores do Campo das Vertentes.

Diante da complexidade e diversidade da realidade, a VAN tem a informação como instrumento para colaborar para a mudança social na região da qual faz parte. Na ótica de Freire (1989), a leitura de mundo é anterior à da palavra, cenário esse em que a leitura crítica de um texto ocorre somente na percepção das relações entre texto e contexto. Assim, a oferta de notícias regionais oferece - aos sujeitos - uma visão de mundo mais consciente.

Ao agir sobre determinada comunidade, a VAN também é condicionada por esses sujeitos, o que constitui um dos cernes da extensão universitária: o processo de intercâmbio e mútua troca de valores, saberes e interfaces culturais. Desse modo, a VAN almeja contribuir para a região das Vertentes, a partir da produção e difusão de conteúdos noticiosos de qualidade, bem como na criação de consciências e leituras críticas do fazer jornalístico.

Em suma, pode-se notar que todas as subcoordenações da VAN estão fundamentadas em princípios educomunicativos, a partir dos quais estudantes mais experientes e mais maduros(sob a coordenação dos docentes envolvidos na iniciativa) compartilham suas vivências na Agência com os novatos. Essa estrutura fomenta a responsabilidade pela transmissão do conhecimento, a proatividade, a articulação vertical e horizontal (tendo em vista a matriz curricular do curso), bem como o exercício de praticas de solidariedade em prol do desenvolvimento da noção de cidadania.

O desafio atual da Agência é a conquista e consolidação dos públicos: leitores diretos na internet, imprensa e novos leitores. O trabalho de fidelização com a primeira parcela da audiência acontece com práticas de fornecimento de informação em formato multimídia na internet, estabelecendo conversações diretas. Para se relacionar melhor com a mídia, a VAN utiliza estratégias de assessoria de comunicação, visando ampliar, facilitar e garantir credibilidade aos conteúdos ofertados para o aproveitamento das mídias tradicionais da região das Vertentes. Por fim, a assessoria de comunicação se articula com práticas educomunicativas para a formação de novos leitores, estudantes do primeiro ano do período noturno da Escola Estadual Dr. Garcia de Lima, localizada em São João del-Rei. 
Este terceiro nicho de público (novos leitores críticos da mídia) - foco do presente artigo - insere-se na concepção de que a informação e a liberdade de expressão são direitos. Assim sendo, o cidadão deve ser incitado a ler, refletir e questionar a qualidade das notícias que tem em mãos por meio da mídia regional. O entendimento das formas de operação da estrutura midiático tende a libertar o sujeito de ideias formatadas da notícia como verdade transcendental. Neste sentido, o objetivo da VAN é proporcionar a elevação do aparato crítico-apreciativo de uma parcela de receptores.

Desta forma, a atividade extensionista de ensino do fazer jornalístico, articulada com práticas educomunicativas, atua como instrumento de empoderamento e mudança social, em que os sujeitos começam a perceber os bastidores de construção da informação. Este constitui, portanto, o primeiro passo para que os jovens desconstruam a impressão de que as notícias sejam espelhos ou retratos fiéis da realidade. Paralelamente, esses cidadãos são convidados a redigir as notícias o seu cotidiano, ou seja, a representar a própria realidade escolar, levandoos a refletir e buscar soluções para as suas questões mais rotineiras tais como qualidade do ensino e alimentação, segurança, justiça e cidadania.

O desvelamento das condições de produção do fazer jornalístico permite, com isso, que o sujeito tenha conhecimento do contexto de produção da informação, desencadeando não apenas a intimidade com esse universo de desenvolvimento de técnicas narrativas e redacionais, bem como da capacidade de aprimoramento do próprio senso crítico.

Conclui-se, portanto, que o jornalismo é uma construção da realidade social perpassada pelos poderes simbólico, econômico e político, os quais estão atrelados ao exercício das indústrias da mídia. A VAN assumiu como missão assegurar parte dos direitos de acesso à informação e liberdade de expressão à comunidade que lhe acolhe. Para tanto, o primeiro passo é o esclarecimento do papel que os cidadãos exercem enquanto leitores de mídia. As oficinas de Mídia Cidadã, abaixo relatadas, revelam que a prática didático e pedagógica para a formação de jovens estudantes no fazer jornalístico tendem a atuar como instrumento de formação, construção e expansão do senso crítico para a realidade em que estão inseridos.

\section{A EXPERIÊNCIA EDUCOMUNICATIVA DA VAN}

O Programa de Extensão Vertentes Agência de Notícias, em sua totalidade, abrange as seguintes áreas: produção de conteúdo jornalístico, assessoria de comunicação e multimeios $\mathrm{O}$ 
processo de elaboração de notícias é realizado a partir da troca de experiências entre veteranos e calouros do Curso de Comunicação/Habilitação Jornalismo da UFSJ. Essa metodologia está inserida na Educomunicação que associa a utilização dos meios de comunicação aos recursos didáticos em sala de aula.

Parafraseando essa estrutura, em agosto de 2013, o Programa iniciou a formação de leitores críticos da mídia, em que a Educomunicação passou a ser realizada no âmbito externo aos trabalhos jornalísticos da VAN. Para tanto, a intervenção feita pelos bolsistas da Agência e um grupo de voluntários aconteceu, em sua primeira fase, na Escola EstadualDr. Garcia de Lima, no município de São João del-Rei, em Minas Gerais.

A parceria entre a referida escola e VAN procurou destacar o papel dos meios de comunicação como recursos didáticos, a partir dos quais os estudantes do Ensino Médio foram empoderados e assumiram as funções de protagonistas na construção de representações sociais da realidade compartilhada por eles no ambiente escolar. $\mathrm{O}$ trabalho foi concebido em formato de "oficinas de mídia cidadã", contendo atividades dinâmicas que não deixassem de interagir com os conteúdos exigidos pela escola, tais como o desenvolvimento da língua portuguesa,a comunicação e expressão de seus interesses, o respeito à organização social e política do ambiente em que atuam como alunos.

O cronograma de trabalho foi construído de forma que, a cada cinco semanas, os estudantes produzissem os próprios relatos jornalísticos para diferentes dispositivos midiáticos: agosto e setembro, jornal mural; outubro, videodocumentários; novembro, blogs; dezembro, spots de rádio.

O espaço foi cedido para essas novas atividades e implementações com os estudantes graças ao Programa Reinventando o Ensino Médio (REM). Elaborado pelo Governo de Minas Gerais, tal iniciativa visa inserir, no Ensino Médio, disciplinas que apresentem possibilidades de conteúdos profissionalizantes e novas áreas do saber. Assim sendo, são disponibilizadas aos alunos três áreas temáticas: Comunicação Aplicada, Tecnologias da Informação e Turismo. A escola Dr. Garcia de Lima foi escolhida como instituição pioneira para implementação desse projeto na cidade.

\section{O PROGRAMA REINVENTANDO O ENSINO MÉDIO}

O programa REM, uma iniciativa da Secretaria de Estado da Educação de Minas Gerais, foi implantado em caráter experimental inicialmente em onze escolas estaduais em 2012, tendo sido expandido no ano posterior e, em função disso, logrando êxito em suas 
aplicações. O REM, já implantado como piloto em 133 escolas da rede pública estadual, será amplamente divulgado, a partir de 2014, sendo levado a todas as escolas estaduais que disponibilizam esse nível de ensino.

Sob a perspectiva de aproximar do mercado de trabalho, por meio de disciplinas profissionalizantes, estudantes do Ensino Médio, o programa visa aumentar a qualidade do ensino, além de proporcionar maior envolvimento e participação por parte dos alunos e deste modo reduzir os índices de evasão escolar.

Ao relacionar o mundo escolar com o mundo do trabalho, o REM oferece a oportunidade de um intercâmbio de vivências que desencadeia o interesse, a preparação e adequação dos jovens para o mercado de trabalho, sendo, portanto, pioneiro no processo de mudança do paradigma do modelo vigente no ensino médio no país.

Com um cronograma orientador já formulado para auxiliar os professores e com o foco voltado para dez áreas de empregabilidade (Comunicação Aplicada; Empreendedorismo e Gestão; Meio Ambiente e Recursos Naturais; Tecnologia da Informação; Turismo; Estudos Avançados em Ciências; Estudos Avançados em Linguagens; Estudos Avançados: Humanidades e Artes; Desenvolvimento Agrícola e Sustentabilidade; e Saúde: Familiar e Coletiva), o REM visa o aproveitamento dos professores já em atuação nas escolas, ofertando, ainda, cursos preparatórios para a aplicação do programa, além de estratégias de acompanhamento periódico dos resultados obtidos.

Em São João del-Rei, o REM foi implantado em 2013 na Escola Estadual Dr. Garcia de Lima, que decidiu trabalhar com as seguintes áreas de empregabilidade: Comunicação Aplicada, Turismo e Tecnologia da Informação.

A professora Ana Cristina Resende (2013), responsável pela disciplina Comunicação Aplicada para os alunos do período noturno da escola, ressalta a importância da iniciativa ao despertar novas áreas de interesse oferecidas pelo programa. Desta forma, o REM beneficia não apenas os estudantes, mas também os educadores, que se tornam aptos a lecionar assuntos relativos a áreas de atuação anteriormente desconhecidas, o que só se torna viável por meio dos cursos preparatórios a que são submetidos.

Apesar de possuir um cronograma padrão a ser seguido, o REM permite a realização de atividades extraclasse e extraturno escolar. Partindo desse pressuposto e com o intuito de promover uma maior adesão por parte dos alunos, a professora Ana Cristina firmou uma parceria com o Programa de Extensão Universitária VAN, desenvolvido no Curso de 
Comunicação Social/Habilitação Jornalismo, da Universidade Federal de São João del Rei (UFSJ).

Assim sendo, essa ação conjunta entre a escola e a Agência de Notícias prima por um viés educomunicativo, partindo da concepção de que educomunicação corresponde a "um novo paradigma de relacionamento entre a comunicação e a educação, em qualquer lugar em que esta ocorra", conforme destaca Soares (2013).

\section{CICLOS FORMATIVOS NA ESCOLA ESTADUAL DR. GARCIA DE LIMA}

O primeiro ciclo formativo de educomunicação foi iniciado em 12 de agosto e focalizou a o desenvolvimento efetivo das rotinas produtivas de um jornal mural dentro da disciplina Comunicação Aplicada, ministrada no período noturno. O processo foi realizado em cinco encontros com, aproximadamente 20 alunos do primeiro ano do Ensino Médio. A referida disciplina já contava com o espaço de duas aulas semanais, às segundas e quartasfeiras. Desse modo, os dinâmicas práticas (abaixo relatadas) ocorriam às segundas-feiras e a professora Ana Cristina Resende articulava os conteúdos teóricos às quartas-feiras.

Começamos com o desenvolvimento de um módulo composto por cinco fases de produção, as quais ocorreram uma vez por semana:

a) Inicialmente, apresentamos o site da VAN e nosso trabalho, explicando como funcionam os bastidores de produção de informações em uma agência de notícias.

b) Na segunda etapa, explicamos alguns conceitos básicos sobre o fazer jornalístico e discutimos as primeiras noções do que são notícia, pirâmide invertida, lide e valores-notícia.

c) Em um terceiro momento, desenvolvemos uma atividade prática (a elaboração dos primeiros textos) orientada pelos bolsistas da VAN, em que os estudantes puderam escolher as temáticas escolares a serem abordadas $\mathrm{e}$ as fontes a serem entrevistadas, assim como definir o enquadramento mais adequado do fato ao gênero notícia.

d) Além disso, promovemos uma fase dedicada às revisões textuais com auxílio de um aluno voluntário do Curso de Letras da UFSJ, em que explicações sobre as edições nos textos desenvolvidos pelos alunos da Escola sanava dúvidas gramaticais ou relativas à análise sintática, dentre outras. Merece destaque o interesse significativo desses estudantes, a partir do momento em que a solução 
das questões tinham um objetivo prático imediato que era a produção do jornal mural da instituição sob a responsabilidade deles.

e) Por fim, a fase de finalização contou com a produção colaborativa dos estudantes da referida instituição de ensino, culminando na apresentação do jornal mural decorado que foi batizado como Manifestação Garcial, nome escolhido pelos alunos da disciplina Comunicação Aplicada. As matérias produzidas foram o primeiro resultado da intervenção da VAN Educomunicativa em escolas públicas.

Nos momentos de atuação em sala de aula dos agentes e voluntários da VAN, a turma dos secundaristas era dividida em grupos, sendo que cada equipe tinha um monitor (bolsista e/ou voluntario) responsável pelo desenvolvimento da dinâmica planejada/organizada para aquele dia. Isso possibilitava um acompanhamento mais próximo e atencioso aos estudantes, repercutindo num melhor rendimento.

Uma estratégia utilizada foi a ideia de produção de pautas relacionadas às demandas da escola percebidas pelos estudantes. Para tanto, os secundaristas foram convidados a indicarem pontos positivos /negativos da instituição, a partir do que foram desenvolvidas questões para elaboração de uma pauta jornalística. Nessa dinâmica, o resultado esperado era a apresentação de uma pauta contendo, no mínimo, três fontes, perguntas para as entrevistas, imagens (fotografias), bem como uma justificativa para o assunto principal abordado.

O resultado da experiência ultrapassou os limites esperados, quando notamos a interação entre os estudantes e os agentes e voluntários do Programa, numa relação educador/educando menos tradicional, mais próxima e bem mais voltada para uma troca produtiva de conhecimentos. Isso possibilitou um melhor aproveitamento do tempo e do interesse dos alunos.

Justamente por ser uma relação orientada, mas não hierarquizada, num primeiro momento, alguns estudantes, no desconhecimento do processo que seria realizado, se mostraram resistentes. Mas, à medida que os encontros foram acontecendo, que as atividades eram realizadas, eles começaram a acreditar no processo e foram se mostrando motivados, interessados. Enfim, esses estudantes puderam perceber que também são capazes de realizar a tarefa proposta, ainda que de forma intuitiva, sem conhecimento efetivamente profissional da técnica e do fazer jornalístico.

Para equipe de bolsistas/voluntários VAN, todo o desenvolvimento do trabalho foi muito enriquecedor. A elaboração/organização de cada encontro, o desafio de estar no comando de atividades em sala de aula e da produção colaborativa, o desafio de aprofundar o 
conhecimento das rotinas jornalísticas ao transmiti-las a alguém absolutamente leigo no assunto, a responsabilidade sobre o conteúdo a ser repassado, o relacionamento com os alunos da Escola construído gradualmente de forma bastante positiva no decorrer dos encontros. Esse panorama possibilitou-nos a percepção de como a Educomunicação pode funcionar na Educação Básica, como conceito e metodologia redentora em prol do resgate do comprometimento do aluno no processo ensino-aprendizagem.

$\mathrm{Na}$ aproximação com os estudantes do Ensino Médio por meio de práticas educomunicativas, a VAN procurou despertar o senso crítico destes jovens diante de notícias que retratavam o cotidiano local, regional e nacional, destacando que as informações por eles recebidas constituem representações da realidade, em que o fato é apresentado de acordo com os filtros a que o redator esta submetido, quaisquer que sejam eles. Similarmente, os estudantes foram empoderados a dialogar, retratar e discutir - dentro dos preceitos jornalísticos - as problemáticas do dia a dia escolar, procurando conhecer a fundo os temas em foco, para além de abordagens superficiais e personalistas.

De acordo com a professora Ana Cristina Resende (2013), após a parceria e a implantação das práticas educomunicativas para a realização do projeto, houve um maior interesse e aderência dos alunos, que se sentiram realmente inseridos e participantes ativos nas atividades sugeridas. A referida educadora ressalta também a importância dessa parceria para o êxito da aplicação prática do programa REM e no significativo crescimento do rendimento dos alunos. Segundo Resende, a dinâmica promovida pela interação das duas realidades possibilita uma maior circulação de informações que se transformam em conhecimento, devido ao envolvimento das duas partes beneficiadas (educandos e educadores).

Desse modo, a interação e o intercâmbio informacional e de saberes, princípios básicos da educomunicação, foram utilizados neste cenário, promovendo a fixação e implementação de conhecimentos que vão possibilitar a aplicação dessas novas conquistas na vida de cada um dos envolvidos.

Cabe notar que, assim como em outras escolas participantes do REM, a Escola Estadual Dr. Garcia de Lima trabalhou pela flexibilização curricular, pela implantação de temas transversais e pela realização de atividades extraclasse e extraescola previstos no cronograma oficial do programa, sendo alem disso inovadora na busca da parceria educomunicativa conquistada. 


\section{CONSIDERAÇÕES FINAIS}

A experiência educomunicativa da VAN na Escola Estadual Dr. Garcia de Lima revela os potenciais transformadores quando se associa a prática da Extensão ao universo da Educação. Os estudantes da referida instituição de ensino foram mais do que capacitados tecnicamente para a escrita jornalística; eles foram empoderados a representar a própria realidade, a perceber e refletir - por meio das técnicas - as questões que atravessam o cotidiano escolar.

O jornal mural vai além de um meio de comunicação e constitui-se um instrumento capaz de elevar o aparato crítico-apreciativo dos estudantes, os quais começam a atuar como agentes multiplicadores dessa iniciativa entre os colegas de outros turnos. Com o despertar do senso de colaboração, ocorre a transformação do aluno da condição de receptor passivo para sujeito ativo e responsável pela construção de um processo ensino-aprendizagem centrado no desenvolvimento da cidadania.

Pela ótica jornalística, foi lançada a semente para a formação de um cidadão melhor, cuja ação no mundo pode ser percebida em atitudes tais como saber ouvir pontos divergentes, respeitar o outro, ponderar sobre os conteúdos e formas de reivindicação, equilibrar os relatos. De modo consonante, tais estudantes puderam vivenciar as rotinas produtivas do jornalismo, percebendo que as notícias são construções linguageiras e podem ser atravessadas por jogos de interesse e poder. Por meio das oficinas empreendidas pela VAN, os participantes passam a ler e entender criticamente as informações e os dispositivos em que estas são veiculadas.

Diante do exposto, entende-se que a intervenção social protagonizada pela parceria entre a VAN e a Escola Estadual Dr. Garcia de Lima indica alguns caminhos transformadores para se trabalhar a mídia como recurso didático no ambiente escolar, bem como reafirma o compromisso da universidade pública com a esfera social.

\section{REFERÊNCIAS}

FREIRE, P. Pedagogia do oprimido. Rio de Janeiro: Paz e Terra, 1978.

FREIRE, P. A importância do ato de ler: em três artigos que se completam. 23 ed. São Paulo: Cortez, 1989. 
KAPLÚN, M. El comunicador popular. 3. ed. Buenos Aires: Lumen-humanitas, 1996.

MARTÍN-BARBERO, J. Retos culturales de la comunicación a la educación. Elementos para una reflexión que está por comenzar. Revista Reflexiones Académicas. N 12 p.45-57, Santiago: Universidad Diego Portales, 2000.

MELO, J. M. de. Educomídia, alavanca da cidadania: o legado utópico de Mario Kaplún. São Bernardo do Campo, UNESCO, UMESP, 2006.

MORAN, J. M. Leituras dos Meios de Comunicação. São Paulo: Pancast, 1993.

PERUZZO, C. M. K. Mídia regional e local: aspectos conceituais e tendências. Comunicação \& Sociedade. São Bernardo do Campo: Póscom-Umesp, a. 26, n. 43, p. 67-84, 1o. sem. 2005.

REDE COMUNICAÇÃO, EDUCAÇÃO E PARTICIPAÇÃO (REDE CEP). Mudando sua escola, mudando sua comunidade, melhorando o Mundo! - Sistematização da Experiência. Brasília: UNICEF, 2010.

RESENDE, A. C. Entrevista concedida a Ana Claudia Lima em 16 set. 2013.

SOARES, I. de O. Comunicação/Educação: a emergência de um novo campo e o perfil de seus profissionais. In: Contato: Revista Brasileira de Comunicação, Educação eArte. Brasília: UNB, ano 1, n. 2, p. 5-75, jan./mar., 1999.

SOARES, I. de O. Um campo emergente de intervenção social. In: Futura. Disponível em: $<$ http://www.futura.org.br/wp-Aontent/uploads/2011/09/Um_campo_emergente_de_ interven\%C3\%A7\%C3\%A3o_social.pdf>. Acesso em: 17 set. 2013.

YIN, R. K. Estudo de caso. Planejamento e métodos. São Paulo: Bookman, 2001.

RECEBIDO EM: 19/09/2013.

APROVADO EM: 21/09/2015. 